\title{
Normal range of BMD in proximal tibia as a different skeletal site at women
}

\author{
Mustafa Arif Aluclu, ${ }^{1}$ Fatih Bati, ${ }^{2}$ Ersoy Kekilli ${ }^{3}$ \\ ${ }^{1}$ Department of Pediatrics, Yenisehir Hospital, Mersin, Turkey \\ 2Department of Nuclear Medicine, Malatya State Hospital, Malatya, Turkey \\ ${ }^{3}$ Department of Nuclear Medicine, Inonu University Faculty of Medicine, Malatya, Turkey
}

\begin{abstract}
OBJECTIVE: Osteoporosis is progressive metabolic bone disease that decreases bone density and features deterioration of bone structure. Dual-energy X-ray absorptiometry (DXA) is commonly used and reliable method to measure bone mineral density (BMD). Aim of this study was to determine normal ranges of BMD in left proximal tibia.

METHODS: Fifty-five females were included in this study. BMD was measured at the lumbar spine and the left proximal tibia using DXA. BMD value of subregions in the left proximal tibia was significantly correlated with BMD value of the total lumbar spine $(r=0.111-0.766)$. New average BMD values of the left proximal tibia were calculated according to age using linear regression formula, leading to average BMD value for the total lumbar spine (L1-L4) in normal population. New simulated T-scores for proximal subregions of the tibia were then calculated.
\end{abstract}

RESULTS: T-scores for proximal subregions were not different from T-scores of total lumbar spine ( $p>0.05)$.

CONCLUSION: It was concluded that proximal tibia is an ideal region for measurement of BMD in osteoporosis.

Keywords: Bone mineral density; correlation; regression; T-score.

$\mathrm{O}$ steoporosis is a progressive skeletal disorder characterized by low bone mass, which causes bone fractures due to decrease in bone mineral density (BMD) and strength [1-6]. Incidence and costs associated with treating osteoporosis are significant socioeconomic burden. Currently, diagnosis of osteoporosis is primarily made based on BMD and bone turnover markers [7]. Bone mineral metabolism can be affected by many factors, such as age, ethnicity, menopause, endocrine-metabolic disease, socioeconomic and sociocultural environment, rural or urban lifestyle, genetics, use of various drugs, physical activity, some diseases, nutrition, and genetics [8]. Another of these factors may be electromagnetic fields [9]. Genetic factors are important in determining peak bone mass and structure, as well as predisposition to bone deterioration and fragility fractures [10]. Osteopo-

Received: December 09, 2016 Accepted: December 20, 2016 Online: January 25, 2017

Correspondence: Dr. Fatih BATI. Malatya Devlet Hastanesi, Nukleer Tip Bolumu, Malatya, Turkey.

Tel: +90 4445634 e-mail: fatihbatimd@gmail.com

(c) Copyright 2016 by Istanbul Northern Anatolian Association of Public Hospitals - Available online at www.kuzeyklinikleri.com 
rosis is the most common metabolic bone disease and is characterized by deterioration of bone microarchitecture structure, decrease in bone mass, and increase in fragility [11-15].

Osteoporosis affects approximately 300 million people worldwide, primarily due to age-related estrogen deficiency in postmenopausal women [16]. With a high content of trabecular bone, osteoporotic fractures are most commonly seen in vertebrae, proximal femur, distal radius, humerus, pelvis, and ribs [17]. The World Health Organization has stated that osteoporosis can be diagnosed by demonstrating reduced BMD in certain bone areas. Dual-energy X-ray absorptiometry (DXA) is an accurate, reliable, and inexpensive method of measurement that allows for diagnosis of osteoporosis before fracture [18]. DXA is widely used to measure BMD [19]. Rapid increase in BMD can be seen discontinuation of treatment. Early or precocious puberty should be treated with gonadotropin-releasing hormone-agonist to prevent permanent short stature [20]. DXA is clinically proven method of measuring BMD in the lumbar spine, proximal femur, and forearm. It is used primarily in diagnosis and management of osteoporosis and other disease states characterized by abnormal BMD, as well as to monitor response to therapy for these conditions. It may also be used to measure whole-body composition [21]. Skeletal deformities such as spinal curve or compression fracture, bowing of long bones, or presence of metal rods can significantly impair DXA results [22]. In a multicenter study in Canada, prevalence of osteoporosis was found to be $12.1 \%$ in the lumbar vertebrae, $7.9 \%$ in the femur neck, and $15.8 \%$ in both the femur neck and the lumbar vertebrae. Incidence of osteoporosis has been reported to be $6 \%$ in those over 50 years of age and $50 \%$ in those over 80 years of age [16]. Rey et al. reported that age-related bone loss was greatest in the forearm $(27 \%-31 \%)$, followed by the proximal femur $(21 \%)$, and less in the lumbar vertebrae (7\%) [23]. Aim of this study was to calculate BMD in regions of the proximal tibia and publish mean and standard deviation values (according to age) for measurement of $\mathrm{T}$ - and $\mathrm{Z}$-scores in women.

\section{MATERIALS AND METHODS}

\section{Patient selection}

A total of 55 women (mean age 49.0 years; range: 26-69 years) who presented at the Department of Nuclear Medicine between October 2011 and March 2012 were enrolled in this study to measure BMD. Study protocol was approved by Malatya clinical research ethics committee. Each volunteer was read patient information form and provided written consent. Patients who were pregnant, had scoliosis, metabolic bone disease, rheumatic bone disease, previous bone fracture in related region, or history of contrast barium or enema radiological examination or radioisotope scan in prior week were not included. Age and anthropometric measurements of all patients were recorded.

Patients were divided into 4 groups according to age. Group I comprised patients between ages of 25 and $39(n=14)$, Group II was made up of patients between ages of 40 and $49(n=14)$, Group III constituted those between ages of 50 and $59(n=14)$, and Group IV patients were between ages of 60 and $69(n=13)$.

\section{Measurement of BMD}

BMD measurements were made using DEXA device (Hologic QDR 4500 W; Hologic Inc, Marlborough, MA, USA). All DXA scans were performed by the same technician. BMD of posterior-anterior lumbar vertebrae (L1-L4) in all patients was measured. BMD and T-scores of patients were calculated automatically according to normal and standard deviation values of Caucasian women using Hologic device database. All patients were measured in supine position. Left tibia was positioned at $180^{\circ}$, straight and parallel to the table. BMD scans of left proximal tibia were performed and BMD values of left proximal tibia regions were calculated using lumbar vertebrae acquisition protocol. Four rectangular regions of interest, each 25 pixels in width, were measured distally from intercondylar eminence (Figure 1). BMD values of these 4 regions were measured in $\mathrm{g} / \mathrm{cm}^{2}$. 


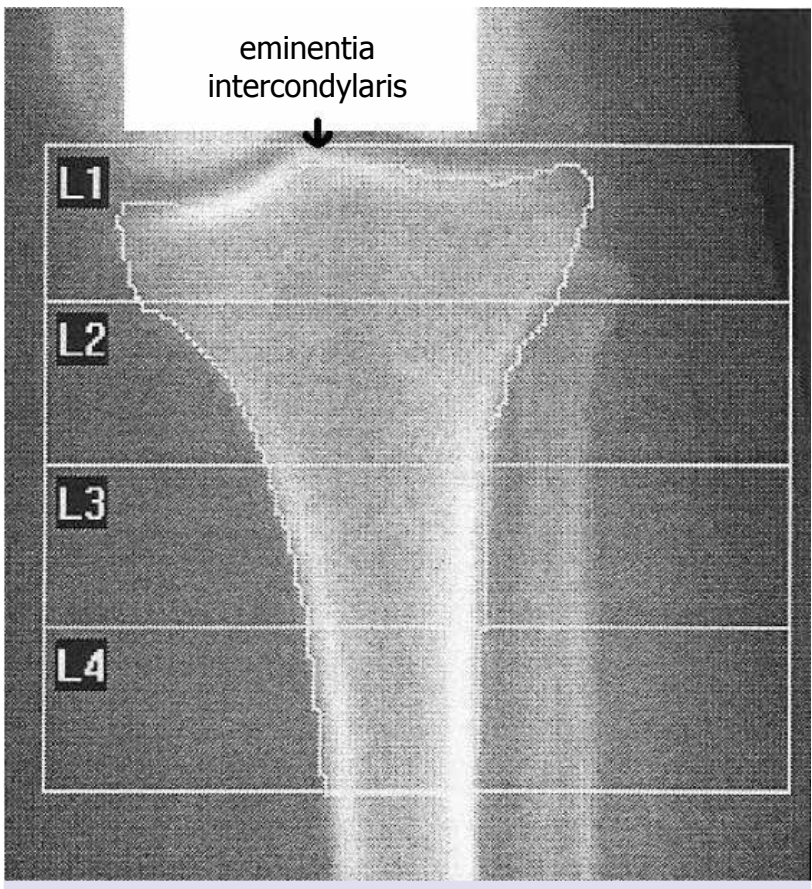

FIGURE 1. Four rectangular regions of interest of left proximal tibia. L: Lumbar.

\section{Statistical analysis}

New average BMD values and new simulated $T$ scores of all subregions in left proximal tibia were calculated according to age using linear regression formula, which yielded average BMD value of the total lumbar spine (L1-L4) in normal population.
New simulated T-scores of proximal tibia subregions were compared with $\mathrm{T}$-scores of total lumbar spine $(p>0.05)$.

Data were expressed as mean $\pm \mathrm{SD}$. Analysis of variance test was applied for comparison of patient anthropometric data, one-tailed Pearson correlation test was used for correlation of BMD values, and Wilcoxon and Friedman tests were used for comparison of simulated T-scores. SPSS (version 16.0; IBM Corp., Armonk, NY, USA) and OpenOffice Calc 3.3 (Apache Software Foundation, Forest Hill, MD, USA) software were used to conduct statistical analysis. $P$ value $<0.05$ was considered statistically significant.

\section{RESULTS}

Descriptive data of cases are presented in Table 1. There was no significant difference between groups $(\mathrm{p}>0.05)$.

Strong relationships were found in comparisons of lumbar vertebrae using Pearson correlation test $(r=0.797-0.962)$. These findings are presented in Table 2. Highest correlation value was between total lumbar vertebrae and the other vertebrae; therefore, total lumbar vertebrae value was used for comparison with proximal tibia regions.

Moderate significant correlations were found

TABLE 1. Descriptive data of patients and statistical comparisons

\begin{tabular}{|c|c|c|c|c|c|}
\hline & $\begin{array}{c}\text { Group I }(n=14) \\
\text { Mean } \pm \text { SD } \\
\text { (Range) }\end{array}$ & $\begin{array}{c}\text { Group II }(n=14) \\
\text { Mean } \pm \text { SD } \\
\text { (Range) }\end{array}$ & $\begin{array}{c}\text { Group III }(n=14) \\
\text { Mean } \pm \text { SD } \\
\text { (Range) }\end{array}$ & $\begin{array}{c}\text { Group IV }(n=14) \\
\text { Mean } \pm \text { SD } \\
\text { (Range) }\end{array}$ & $p$ \\
\hline $\begin{array}{l}\text { Age } \\
\text { (years) }\end{array}$ & $\begin{array}{c}33.0 \pm 1.1 \\
(26.0-40.0)\end{array}$ & $\begin{array}{c}45.0 \pm 0.8 \\
(41.0-49.0)\end{array}$ & $\begin{array}{c}54.7 \pm 0.7 \\
(51.0-60.0)\end{array}$ & $\begin{array}{c}64.3 \pm 0.8 \\
(61.0-70.0)\end{array}$ & \\
\hline $\begin{array}{l}\text { Weight } \\
(\mathrm{kg})\end{array}$ & $\begin{array}{c}61.6 \pm 3.5 \\
(42.0-90.0)\end{array}$ & $\begin{array}{c}70.0 \pm 2.7 \\
(55.0-88.0)\end{array}$ & $\begin{array}{c}72.9 \pm 4.3 \\
(55.0-100.0)\end{array}$ & $\begin{array}{c}70.0 \pm 1.9 \\
(60.0-80.0)\end{array}$ & 0.150 \\
\hline $\begin{array}{l}\text { Height } \\
(\mathrm{cm})\end{array}$ & $\begin{array}{c}158.7 \pm 1.4 \\
(150.0-168.0)\end{array}$ & $\begin{array}{c}161.0 \pm 1.5 \\
(150.0-170.0)\end{array}$ & $\begin{array}{c}158.2 \pm 1.2 \\
(150.0-165.0)\end{array}$ & $\begin{array}{c}155.9 \pm 1.6 \\
(145.0-163.0)\end{array}$ & 0.156 \\
\hline $\begin{array}{l}\text { BMI } \\
\left(\mathrm{kg} / \mathrm{m}^{2}\right)\end{array}$ & $\begin{array}{c}25.3 \pm 1.7 \\
(16.8-41.9)\end{array}$ & $\begin{array}{c}27.0 \pm 1.1 \\
(21.4-35.5)\end{array}$ & $\begin{array}{c}28.8 \pm 1.3 \\
(21.8-37.4)\end{array}$ & $\begin{array}{c}28.8 \pm 0.7 \\
(24.6-35.5)\end{array}$ & 0.113 \\
\hline
\end{tabular}

SD: Standard deviation; BMI: Body mass index. 
TABLE 2. Correlation analysis of bone mineral density value of lumbar vertebra

\begin{tabular}{|c|c|c|c|c|c|}
\hline & L1 & L2 & L3 & L4 & LT \\
\hline \multicolumn{6}{|l|}{ L1 } \\
\hline$r$ & 1 & $0.914 * *$ & $0.855^{* *}$ & $0.797 * *$ & $0.928 * *$ \\
\hline$p$ & & $p<0.001$ & $\mathrm{p}<0.001$ & $p<0.001$ & $p<0.001$ \\
\hline \multicolumn{6}{|l|}{ L2 } \\
\hline$r$ & $0.914 * *$ & 1 & $0.901^{* *}$ & $0.813^{* *}$ & $0.952 * *$ \\
\hline$p$ & $p<0.001$ & & $p<0.001$ & $p<0.001$ & $p<0.001$ \\
\hline \multicolumn{6}{|l|}{ L3 } \\
\hline$r$ & $0.855^{* *}$ & $0.901^{* *}$ & 1 & $0.859 * *$ & $0.962 * *$ \\
\hline$p$ & $p<0.001$ & $p<0.001$ & & $p<0.001$ & $p<0.001$ \\
\hline \multicolumn{6}{|l|}{ L4 } \\
\hline$r$ & $0.797 * *$ & $0.813^{* *}$ & $0.859 * *$ & 1 & $0.931 * *$ \\
\hline$p$ & $p<0.001$ & $p<0.001$ & $p<0.001$ & & $p<0.001$ \\
\hline \multicolumn{6}{|l|}{ LT } \\
\hline$r$ & $0.928^{* *}$ & $0.952^{* *}$ & $0.962 * *$ & $0.931^{* *}$ & 1 \\
\hline $\mathrm{p}$ & $p<0.001$ & $p<0.001$ & $\mathrm{p}<0.001$ & $p<0.001$ & \\
\hline
\end{tabular}

L1: First lumbar vertebra; L2: Second lumbar vertebra; L3: Third lumbar vertebra; L4: Fourth lumbar vertebra; LT: Total lumbar vertebrae (L1-4). r: Correlation coefficient.

TABLE 3. Correlation analysis between bone mineral density value of lumbar vertebrae and tibial regions

\begin{tabular}{|c|c|c|c|c|c|c|c|}
\hline & & & $\mathrm{T} 1$ & $\mathrm{~T} 2$ & T3 & T4 & $\pi$ \\
\hline \multirow[t]{2}{*}{ Group I $(n=14)$} & LT & $r$ & 0.448 & $0.487^{*}$ & $0.611^{*}$ & $0.487 *$ & $0.538 *$ \\
\hline & & $\mathrm{p}$ & 0.054 & 0.039 & 0.010 & 0.039 & 0.024 \\
\hline \multirow[t]{2}{*}{ Group II $(n=14)$} & LT & $r$ & 0.378 & 0.356 & 0.322 & 0.111 & 0.337 \\
\hline & & $\mathrm{p}$ & 0.091 & 0.105 & 0.130 & 0.352 & 0.119 \\
\hline \multirow[t]{2}{*}{ Group III $(n=14)$} & LT & $r$ & $0.691^{* *}$ & $0.592^{*}$ & $0.564 *$ & $0.625^{* *}$ & $0.674 * *$ \\
\hline & & $\mathrm{p}$ & 0.003 & 0.013 & 0.018 & 0.008 & 0.004 \\
\hline \multirow[t]{2}{*}{ Group IV $(n=13)$} & LT & $r$ & $0.553 *$ & $0.766^{* *}$ & $0.738^{* *}$ & $0.705^{* *}$ & $0.741 * *$ \\
\hline & & $\mathrm{p}$ & 0.025 & 0.001 & 0.002 & 0.004 & 0.002 \\
\hline \multirow[t]{2}{*}{ Total $(n=55)$} & LT & $r$ & $0.588^{* *}$ & $0.559 * *$ & $0.561^{* *}$ & $0.525^{* *}$ & $0.601 * *$ \\
\hline & & $\mathrm{p}$ & 0.0001 & 0.0001 & 0.0001 & 0.0001 & 0.0001 \\
\hline
\end{tabular}

L1: First lumbar vertebra; L2: Second lumbar vertebra; L3: Third lumbar vertebra; L4: Fourth lumbar vertebra; LT: Total lumbar vertebrae (L1-4); T1: First tibial region of interest; T2: Second tibial region of interest; T3: Third tibial region of interest; T4: Fourth tibial region of interest; TT: Sum of areas in the tibia; r: Correlation coefficient.

between lumbar vertebrae and tibia region $\mathrm{BMD}$ values $(r=0.111-0.766)$. When Group II was excluded, correlation was higher than previous measurement $(r=0.448-0.766)$ (Table 3).
Using each patient's BMD values, linear regression curve and formula were obtained for all groups showing relationship between total lumbar vertebrae and each region of proximal tibia (Figure 2 and Table 4). 


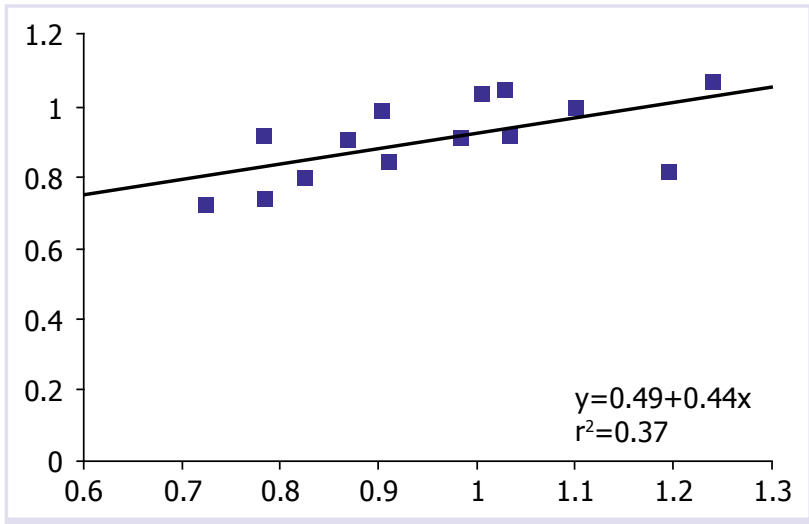

FIGURE 1. Linear regression curve and formula for groups indicating the relationship between bone mineral density values of total lumbar vertebrae and second region of proximal tibia.

According to age, new average \pm SD BMD values for all subregions of proximal tibia were calculated using linear regression formula, leading to average BMD value for the total lumbar spine (L1-L4) of normal population of Caucasian women based on Hologic database (Table 5).

Then, according to new average $\pm \mathrm{SD} \mathrm{BMD}$ in all subregions, new simulated $\mathrm{T}$-scores for each left proximal tibia subregion were calculated for each patient. In Groups I through III, new simulated Tscores of subregions were not different from $T$-score of total lumbar spine ( $p>0.05)$ (Table 6). In Group $I V$, simulated $T$-scores of proximal tibia differed from $T$-score of total lumbar vertebrae $(p=0.006)$. When first region of proximal tibia is excluded, no significant differences were found between lumbar spine $T$-scores and simulated $T$-score of each proximal tibia region ( $p>0.05)$.

\section{DISCUSSION}

As a result of the present study, it has been demonstrated that the proximal tibia area can be used to measure and evaluate BMD. Abrahamsen et al. found statistically significant correlation for BMD values, $T$-score and $Z$-score among lumbar spine, proximal femur, and forearm in their study of 2005 healthy perimenopausal women $(r=0.40-0.77$; $\mathrm{p}<0.01)$. Correlation of $\mathrm{T}$-scores was higher be-
TABLE 4. Linear regression formulas of all groups and relationship between total lumbar vertebrae and each proximal tibia region

\begin{tabular}{|c|c|c|c|}
\hline & & Linear regression formulas & $r^{2}$ \\
\hline \multirow[t]{5}{*}{ Group I } & Lt-T1 & $y=0.7+0.26 x$ & 0.2 \\
\hline & Lt-T2 & $y=0.64+0.33 x$ & 0.24 \\
\hline & Lt-T3 & $y=0.49+0.44 x$ & 0.37 \\
\hline & Lt-T4 & $y=0.54+0.33 x$ & 0.24 \\
\hline & Lt-TT & $y=0.57+0.37 x$ & 0.29 \\
\hline \multirow[t]{5}{*}{ Group II } & Lt-T1 & $y=0.66+0.28 x$ & 0.14 \\
\hline & Lt-T2 & $y=0.62+0.32 x$ & 0.13 \\
\hline & Lt-T3 & $y=0.63+0.27 x$ & 0.1 \\
\hline & Lt-T4 & $y=0.77+0.1 x$ & 0.01 \\
\hline & Lt-TT & $y=0.63+0.29 x$ & 0.11 \\
\hline \multirow[t]{5}{*}{ Group III } & Lt-T1 & $y=0.38+0.6 x$ & 0.48 \\
\hline & Lt-T2 & $y=0.22+0.79 x$ & 0.35 \\
\hline & Lt-T3 & $y=0.12+0.77 x$ & 0.32 \\
\hline & Lt-T4 & $y=0+0.79 x$ & 0.39 \\
\hline & Lt-TT & $y=0.15+0.81 x$ & 0.45 \\
\hline \multirow[t]{5}{*}{ Group IV } & Lt-T1 & $y=0.61+0.26 x$ & 0.05 \\
\hline & Lt-T2 & $y=0.09+0.96 x$ & 0.49 \\
\hline & Lt-T3 & $y=0.09+0.8 x$ & 0.35 \\
\hline & Lt-T4 & $y=0.07+0.73 x$ & 0.37 \\
\hline & Lt-TT & $y=0.16+0.8 x$ & 0.32 \\
\hline
\end{tabular}

LT: Total lumbar vertebrae (L1-4); T1: First tibial region of interest; T2: Second tibial region of interest; T3: Third tibial region of interest; T4: Fourth tibial region of interest; $\mathrm{TT}$ : Sum of areas in the tibia.

tween the proximal femur and the lumbar spine $(r=0.67 ; p<0.01)[21]$. In our study, we found high correlation among $\mathrm{T}$-scores of lumbar vertebrae $(\mathrm{r}=0.111-0.766)$.

Previous studies found BMD values of lumbar vertebrae in Turkey calculated using quantitative computed tomography and DXA device were similar to those of Western countries [5, 24]. In our study, BMD and T-scores of total lumbar vertebrae were used as reference for comparisons.

Regression analysis and regression curves are commonly used to determine risk factors for osteoporosis but calculation of normal values and standard derivation of BMD using regression formula was not found in literature search.

Bone densitometry has been performed on the 
TABLE 5. New average \pm SD bone mineral density values in all proximal tibia subregions

\begin{tabular}{lcccccc} 
Age (years) & $L T$ & $\mathrm{~T} 1 \pm \mathrm{SD}$ & $\mathrm{T} 2 \pm \mathrm{SD}$ & $\mathrm{T} 3 \pm \mathrm{SD}$ & $\mathrm{T} 4 \pm \mathrm{SD}$ & $\mathrm{TT} \pm \mathrm{SD}$ \\
\hline 20 & 1.070 & $1.423 \pm 0.500$ & $1.303 \pm 0.394$ & $1.318 \pm 0.296$ & $1.606 \pm 0.394$ & $1.351 \pm 0.352$ \\
25 & 1.060 & $1.385 \pm 0.500$ & $1.273 \pm 0.394$ & $1.295 \pm 0.296$ & $1.576 \pm 0.394$ & $1.324 \pm 0.352$ \\
30 & 1.040 & $1.308 \pm 0.500$ & $1.212 \pm 0.394$ & $1.250 \pm 0.295$ & $1.515 \pm 0.394$ & $1.270 \pm 0.352$ \\
35 & 1.030 & $1.269 \pm 0.500$ & $1.182 \pm 0.394$ & $1.227 \pm 0.296$ & $1.485 \pm 0.394$ & $1.243 \pm 0.352$ \\
40 & 1.020 & $1.067 \pm 0.216$ & $1.013 \pm 0.164$ & $1.169 \pm 0.169$ & $1.291 \pm 0.165$ & $1.074 \pm 0.161$ \\
45 & 1.000 & $1.033 \pm 0.217$ & $0.987 \pm 0.165$ & $1.143 \pm 0.169$ & $1.266 \pm 0.164$ & $1.049 \pm 0.161$ \\
50 & 0.990 & $1.017 \pm 0.216$ & $0.975 \pm 0.164$ & $1.130 \pm 0.169$ & $1.253 \pm 0.165$ & $1.037 \pm 0.161$ \\
55 & 0.970 & $0.983 \pm 0.217$ & $0.949 \pm 0.165$ & $1.104 \pm 0.169$ & $1.228 \pm 0.164$ & $1.012 \pm 0.161$ \\
60 & 0.960 & $1.346 \pm 0.216$ & $0.906 \pm 0.09$ & $1.088 \pm 0.09$ & $1.219 \pm 0.09$ & $1.000 \pm 0.086$ \\
65 & 0.940 & $1.269 \pm 0.217$ & $0.885 \pm 0.09$ & $1.063 \pm 0.09$ & $1.192 \pm 0.09$ & $0.975 \pm 0.086$ \\
70 & 0.930 & & & & & \\
75 & 0.920 & & & & & \\
80 & 0.900 & & & & & \\
85 & 0.890 & & & & & \\
\hline
\end{tabular}

SD: Standard deviation; LT: Total lumbar vertebrae (L1-4); T1: First tibial region of interest; T2: Second tibial region of interest; T3: Third tibial region of interest; T4: Fourth tibial region of interest; TT: Sum of areas in the tibia.

TABLE 6. New simulated T-scores of each proximal tibia region

\begin{tabular}{lcccc} 
Group I $(\mathrm{n}=14)$ & Group II $(\mathrm{n}=14)$ & $\begin{array}{c}\text { Group III }(\mathrm{n}=14) \\
\text { Mean } \pm \text { SD (Range) }\end{array}$ & $\begin{array}{c}\text { Mean } \pm \text { SD (Range) } \\
\text { (Range) }\end{array}$ & $\begin{array}{c}\text { Group IV }(\mathrm{n}=14) \\
\text { Mean } \pm \text { SD (Range) }\end{array}$ \\
\hline LTTs & $-1.271 \pm 1.028$ & $-1.729 \pm 0.100$ & $-1.757 \pm 1.516$ & $-2.646 \pm 0.907$ \\
T1Ts & $-1.029 \pm 0.412$ & $-1.336 \pm 0.752$ & $-1.029 \pm 0.849$ & $-3.015 \pm 0.590$ \\
T2Ts & $-1.050 \pm 0.449$ & $-1.379 \pm 0.796$ & $-1.021 \pm 0.742$ & $-2.092 \pm 1.026$ \\
T3Ts & $-1.036 \pm 0.573$ & $-1.529 \pm 0.833$ & $-1.029 \pm 0.698$ & $-2.531 \pm 1.027$ \\
T4Ts & $-1.107 \pm 0.478$ & $-1.571 \pm 0.841$ & $-1.029 \pm 0.785$ & $-2.669 \pm 1.144$ \\
TTTs & $-1.129 \pm 0.484$ & $-1.400 \pm 0.857$ & $-0.993 \pm 0.862$ & $-2.592 \pm 1.074$ \\
P value & 0.452 & 0.167 & 0.743 & 0.0001
\end{tabular}

SD: Standard deviation; BMI: Body mass index; T1Ts: T-scores of first tibial region of interest; T2Ts: T-scores of second tibial region of interest; T3Ts: T-scores of third tibial region of interest; T4Ts: T-scores of fourth tibial region of interest. TTTs: T-scores of the sum of areas in the tibia.

lumbar spine, the proximal femur, and the forearm. Previous studies have indicated that sclerotic changes increase T-scores of lumbar vertebrae. Removing sclerotic area from assessment allows for more accurate $\mathrm{T}$ - and $\mathrm{Z}$-scores. Depending on excluded area, 1 patient may generate different scores. This can be observed in different scan areas, such as the proximal femur and the forearm [25-28].
BMD values of distal tibia in children have been measured using DXA and quantitative computed tomography in previous studies $[29,30]$. BMD measurements in proximal tibia have typically been published in cases of total knee arthroplasty [31].

In present study, mean and standard deviation values of BMD in proximal tibia were calculated using regression curve and formula from $\mathrm{T}$-scores 
of total lumbar vertebrae. Regions of interest used were also original.

New average BMD values of left proximal tibia were calculated according to age using linear regression formula, which yielded average BMD value of the total lumbar spine (L1-L4) in normal population. New simulated T-scores of proximal tibia subregions were then calculated. New simulated T-scores of proximal tibia subregions were not different from $T$-scores of the total lumbar spine ( $p>0.05)$. We concluded that proximal tibia is an ideal evaluation region to measure BMD for diagnosis of osteoporosis. Increase in average life span indicates osteoporosis will become even more serious problem in the near future. For this reason, determination of BMD and early bone loss in different anatomical regions is very important.

\section{Conflict of Interest: None declared.}

Financial Disclosure: The authors declared that this study has received no financial support.

Authorship contributions: Concept - M.A.A.; Design M.A.A.; Supervision - M.A.A.; Materials - M.A.A.; Data collection \&/or processing - M.A.A.; Analysis and/or interpretation - F.B.; Literature search - M.A.A.; Writing - F.B.; Critical review - E.K.

\section{REFERENCES}

1. Lundeen GA, Knecht SL, Vajda EG, Bloebaum RD, Hofmann AA. The contribution of cortical and cancellous bone to dual-energy X-ray absorptiometry measurements in the proximal femur. Osteoporos Int 2001;12:192-8. Crossre.

2. Brown JP, Fortier M, Frame H, Lalonde A, Papaioannou A, Senikas V, et al. Canadian consensus conference on osteoporosis, J Obstet Gynaecol Can 2006;28:95-112. Crossre.

3. Kanis JA. Diagnosis of osteoporosis. Osteoporos Int 1997;7:108-16. Crossret

4. Fink HA, Harrison SL, Taylor BC, Cummings SR, Schousboe JT, Kuskowski MA, et al. Differences in site-specific fracture risk among older women with discordant results for osteoporosis at hip and spine: study of osteoporotic fractures. J Clin Densitom 2008;11:250-9. Crossret

5. Paker N, Erbil M, Otlu Z, Soy D, Uysal E. Bone mineral density in healthy Turkish women. J Miner Stoffwechs 2005;12:73-6.

6. Garg MK, Kharb S. Dual energy X-Ray absorptiometry: Pitfalls in measurement and interpretation of bone mineral density. Indian Journal of Endocrinology and Metabolism 2013;17:203-10.

7. Lv H, Jiang F, Guan D, Lu C, Guo B, Chan C, et al. Metabolo- mics and Its Application in the Development of Discovering Biomarkers for Osteoporosis Research. Int J Mol Sci 2016;17:2018.

8. Ediz L, Dülger AC, Toprak M, Ceylan MF, Kemik O. The prevalence and risk factors of decreased bone mineral density in firstly diagnosed ulcerative colitis patients in the eastern region of Turkey. Int J Clin Exp Med 2011;4:157-63.

9. Cidem M, Bahadir C, Karakoc Y, Karacan I. Forearm bone min eral density in healthy young adult mobile phone users. MedScience 2012;1:35-40.

10. Marini F, Cianferotti L, Brandi ML. Epigenetic mechanisms in bone biology and osteoporosis: Can they drive therapeutic choices? International Journal of Molecular Sciences 2016;17:1329.

11. World Health Organization Study Group. Assessment of fracture risk and its application to screening for postmenopausal osteoporosis. Report of a WHO Study Group, World Health Organ Tech Rep 1994;843:1-129.

12. Keen RW. Osteoporosis: strategies for prevention and management. Best Practice \& Research Clinical Rheumatology 2007;21:109-22. Crossrel

13. Kanis JA, Melton LJ, Christiansen C, Johnston CC, Khaltaev N. The diagnosis of osteoporosis. J Bone Miner Res 1994;9:1137-41

14. Erhan B, Gunduz B. The Effect of Fracture on Quality of Life in Postmenopausal Osteoporotic Women. Osteoporoz Dünyasından 2006;12:31-4.

15. Erkin G, Akınbingöl M, Didere Gülşen E, Aybay C, Özel S. The features of the geriatric Patients who have bone mineral Dansitometric measurements in Our osteoporosis unit. Türk Geriatri Dergisi 2004;7:84-8.

16. Shu R, Ai D, Bai D, Song J, Zhao M, Han X. The effects of SOST on implant osteointegration in ovariectomy osteoporotic mice. Arch Oral Biol 2016;74:82-91. Crossret

17. Court-Brown C. Osteoporotic fractures. In: Court-Brown C, McQueen MM, Tornetta P, editors. Trauma. 1st ed. Philadelphia: Lippincott Williams and Wilkins, 2006. p. 54-8.

18. Bone Mineral Density: What it Means and How to Measure it. Available at: http://www.oif.org/site/DocServer/Bone_Mineral_Density.pdf?docID=7185. Accessed December 12, 2016.

19. Genant HK, Njeh CE. Update on the diagnosis of osteoporosis. Current Orthopedics 1999;13:144-55. Crossre]

20. Kekilli E, Aluclu MA, Bati F, Koksal İ. Lumbar spine and proximal femur BMD values in Turkish girls and the effect of precocious puberty on BMD. Med-Science 2012;1:188-99. Crossre

21. American College of Radiology (ACR) and Society of Skeletal Radiology (SSR). Practice guideline for the performance of dual-energy $\mathrm{x}$-ray absorptiometry (DXA). Revised 2013;1-14.

22. Abrahamsen B, Hansen TB, Jensen LB, Hermann AP, Eiken P. Site of osteodensitometry in peri menopausal women: correlation and limits of agreement between anatomic regions. J Bone Miner Res 1997;12:1471-9. Crossret

23. Rey P, Sornay-Rendu E, Garnero P, Vey-Marty B, Delmas PD. Measurement of bone density in the wrist using $\mathrm{X}$-ray absorptiometry: comparison with measurements of other sites. Rev Rhum Ed Fr 1994;61:619-26. 
24. Dinç H, Sadikoğlu Y, Savci G, Demirci A, Tuncel E. Bone mineral density measurement by quantitative computed tomography in a normal Turkish population. Eur J Radiol 1995;21:79-83.

25. Jacobson JA, Jamadar DA, Hayes CW. Dual X-ray absorptiometry: recognizing image artifacts and pathology. AJR 2000;174:1699-705. Crossre-

26. Bonnick SL. Bone Densitometry in Clinical Practice. 3rd ed. New York: Humana Press 1998:48-50.

27. Siminoski K, Leslie WD, Frame H, Hodsman A, Josse RG, Khan A, et al. Recommendations for bone mineral density reporting in Canada. Can Assoc Radiol J 2005;56:178-88.

28. Syed Z, Khan A. Bone densitometry: applications and limita- tions. J Obstet Gynaecol Can 2002;24:476-84. Crossree

29. Zemel BS, Stallings VA, Leonard MB, Paulhamus DR, Kecskemethy $\mathrm{HH}$, Harcke HT, et al. Revised pediatric reference data for the lateral distal femur measured by Hologic Discovery/Delphi dual-energy X-ray absorptiometry. J Clin Densitom 2009;12:207-18. Crossre

30. Tryon E, Szalay EA. The lateral distal femoral DEXA scan in children: a chronology of growing bone? Orthopedics 2008;31:1093.

31. Sievänen H, Oja P, Vuori I. Precision of dual energy x-ray absorptiometry in determining bone mineral density and content of various skeletal sites. J Nucl Med 1992;33:1137-42. 